\title{
ENSINO FUNDAMENTAL DE NOVE ANOS: Um estudo da percepção das equipes de direção de escolas públicas de um municipio do Estado de São Paulo*
}

\author{
NINE YEAR LONG PRIMARY EDUCATION: a study on \\ state school headteachers' perceptions
}

\author{
Graziela Zambão Abdian Maia** \\ Cláudia Vieira Camillo***
}

\begin{abstract}
Resumo
O presente artigo apresenta uma análise da percepção das equipes de direção das escolas municipais de um município do interior paulista a respeito do processo de concretização do Ensino Fundamental de nove anos. A pesquisa foi realizada envolveu a análise de entrevistas semi-estruturadas com o dirigente municipal e com os diretores e vice-diretores das escolas envolvidas; a análise da legislação nacional e estadual e a identificação das principais diretrizes propostas pelos profissionais do município e das dificuldades e êxitos vivenciados pelas escolas municipais. Entre os resultados, destaca-se a percepção positiva dos integrantes da organização escolar em relação à política educacional traçada, sendo que os maiores problemas evidenciados concentraram-se em questões mais operacionais e técnicas do que de opção política.
\end{abstract}

Palavras- chave: Organização escolar. Ensino Fundamental. Gestão escolar.

\begin{abstract}
This article analyzes the perceptions of municipal school principals in a city of the state of São Paulo concerning the implementation of the nine-year-long elementary education system. The data collection instruments included semi-structured interviews with the city's chairman of the Board of Education as well as with principals and vice principals. The researchers considered city and state legislation, identified the main guidelines proposed by municipal professionals and also the difficulties and victories experienced by city schools. The highlights of the results found a positive perception by professionals of the established Educational Policy. The major problems pointed out in the interviews refer to the operational and technical issues rather than on political choice.
\end{abstract}

Keywords: School Organization. Elementary School. School management.

\section{Introdução}

As reflexões apresentadas originaram-se da necessidade e da importância de se compreender como as escolas se apropriam das reformas educacionais, especificamente, do projeto de implantação do ensino de nove anos, e como elas são engendradas pelos integrantes da organização escolar. Os objetivos que nortearam a pesquisa foram: realizar um diagnóstico da percepção do dirigente municipal e dos diretores de escola sobre o processo de concretização do ensino de nove anos; levantar e analisar a legislação pertinente à temática, nos âmbitos nacional, estadual e municipal; e identificar as possíveis dificuldades e êxitos do processo nas escolas e na Secretaria Municipal.

Para a investigação, foram coletados dois tipos de material. O primeiro, bibliográfico/documental, consistiu no levantamento dos temas e documentos referentes à temática. $\mathrm{O}$ segundo material foi obtido mediante a transcrição das entrevistas realizadas com a dirigente municipal e com os (as) diretores (as) de seis escolas municipais, duas creches, duas Escolas de Educação Infantil (EMEls) e duas escolas de Ensino Fundamental (EMEFs) de um município com aproximadamente 60 mil habitantes.

Este artigo focaliza a análise das entrevistas semiestruturadas, sendo que, primeiramente, aborda a legislação pertinente ao ensino de nove anos, prossegue com a análise da percepção das equipes de direção e da dirigente municipal e finaliza tecendo algumas considerações conclusivas sobre o exposto.

Optou-se pela realidade específica de um município no interior de São Paulo, com cerca de 60 mil habitantes, próximo ao município de Marília, onde está instalada a Faculdade de Filosofia e Ciências da Universidade Estadual Paulista (UNESP). Realizouse visita na Secretaria de Educação daquele município com a intenção de se elaborar um projeto de ex-

\footnotetext{
"Financiamento: FAPESP (Fundação de Amparo à Pesquisa do Estado de São Paulo)

** Docente do PPGE - Faculdade de Filosofia e Ciências de Marília (UNESP). E-mail: graziela.maia@gmail.com

B** Bolsista de pesquisa da FAPESP. E-mail: cvieira65@hotmail.com
} 
tensão que privilegiasse a formação continuada da gestão das escolas. As pesquisadoras notaram que, em seu discurso, a dirigente evidenciava o processo de concretização do Ensino Fundamental de nove anos, utilizando-o como argumento para não aceitar o vínculo universidade-escola de formação continuada. A dirigente também destacou que, no momento, realizavam-se discussões e debates coletivos envolvendo a comunidade, as escolas e a Secretaria, e que o processo se mostrava rico e interessante para a realização de pesquisa científica.

Inúmeras questões surgiram: o que permeava a tomada de decisão? Seria um compromisso político com as classes populares? Quais seriam os problemas vivenciados do ponto de vista administrativo? Iniciaram-se, desse modo, leituras e aprofundamento teórico que culminaram na elaboração de um projeto de pesquisa que obteve apoio financeiro da Fundação de Amparo à Pesquisa do Estado de São Paulo (FAPESP).

O principal instrumento de pesquisa foi a realização, transcrição e análise de entrevistas semiestruturadas com os (as) diretores (as) e vice-diretores (as) de seis escolas municipais, duas creches, duas escolas de Educação Infantil (EMEls) e duas escolas de Ensino Fundamental (EMEFs). A dirigente solicitou que, anteriormente à realização das entrevistas, as equipes de direção das escolas tivessem a oportunidade de ser apresentadas aos objetivos da pesquisa. As entrevistas foram realizadas conforme a disponibilidade dos entrevistados, em dias alternados e marcados pelos próprios, com o intuito de se respeitar os cotidianos das escolas.

\section{Algumas considerações sobre 0 Ensino Fundamental de nove anos}

A questão da obrigatoriedade escolar não é recente em nosso país, uma vez que esteve presente em diferentes momentos da história da educação que sinalizaram para o aumento do período de duração do ensino obrigatório. A primeira Lei de Diretrizes e Bases da Educação Nacional ( $n^{\circ}$. 4.024/61) definiu quatro anos de ensino obrigatório às crianças com idade de 7 anos, sendo que o Brasil se comprometeu, naquele período, a ampliar a obrigatoriedade para seis anos até 1970. (BRASIL, 1961).

A Lei que reformou o primeiro e segundo graus ( $n^{\circ}$. 5692/ 71 ) definiu, em seu artigo $19^{\circ}$, oito anos de ensino obrigatório e o ingresso no ensino de $1^{\circ}$ grau (hoje Ensino Fundamental) das crianças com idade mínima de 7 anos. O mesmo artigo abriu a possibilidade de que cada sistema de ensino dispusesse sobre a matrícula de crianças mais jovens e foi recomendado que os menores de 7 anos fossem matriculados em escolas maternais e jardins de infância. (BRASIL, 1971).
Em 1996, a Lei de Diretrizes e Bases da Educação Nacional (LDBEN nº.9394/96) sinalizou para o Ensino Fundamental obrigatório de nove anos ao indicar que os municípios poderiam matricular, de forma facultativa, alunos de 6 anos no Ensino Fundamental se já tivessem cumprido com sua responsabilidade em relação às crianças de 7 anos. (BRASIL, 1996).

A orientação é explicitada no Plano Nacional de Educação (Lei n. 10.172/01), nos seguintes termos: "Ampliar para nove anos a duração do Ensino Fundamental obrigatório com início aos 6 anos, à medida que for sendo universalizado o atendimento na faixa dos 7 aos 14 anos." (BRASIL, 2001).

Com a Lei n. 11.114/05 (BRASIL, 2005a), as matrículas de crianças com 6 anos de idade passaram a ser obrigatórias no Ensino Fundamental, a partir do início do ano letivo subsequente. Esse dispositivo que altera quatro artigos $\left(6^{\circ}, 30^{\circ}, 32^{\circ}\right.$ e $\left.87^{\circ}\right)$ da LDBEN n. 9394/96, hoje afrouxado por emendas que alargaram seu prazo de implantação e implementação, deu embasamento legal aos inúmeros municípios que já vinham desenvolvendo a prática de matricular no Ensino Fundamental crianças com 6 anos de idade, completos ou não, visando a ampliar a cota de recursos distribuídos pelo Fundo de Manutenção e Desenvolvimento do Ensino Fundamental e de Valorização do Magistério (FUNDEF). (ALVES, 2007).

No Art. $1^{\circ}$, alterando o artigo $6^{\circ}$ da LDBEN, esta mesma Lei determina que: "É dever dos pais ou responsável efetuar a matrícula dos menores, a partir dos 6 anos de idade no Ensino Fundamental." Já o artigo 87, ao ser alterado, reza que cada município e, supletivamente, o Estado e a União, deverá matricular todos os educandos a partir dos 6 anos de idade no Ensino Fundamental, atendidas algumas condições, no âmbito da cada sistema de ensino. ${ }^{1}$

No mesmo ano, foram publicados, em âmbito nacional, dois Pareceres que se referem à proposta do ensino de nove anos. O Parecer CNE/CEB $n^{\circ}$. 6/2005 (BRASIL, 2005b) reexamina o Parecer CNE/ CEB n. 24/2004, que visou ao estabelecimento de normas nacionais para a ampliação do Ensino Fundamental para nove anos e, entre outros aspectos, ressalta que a legislação nacional aprovada (CF de 1988; LDBEN de 1996; Plano Nacional de Educação) contemplava alternativas para alcançar o objetivo maior da garantia do padrão de qualidade do

\footnotetext{
${ }^{1}$ a) Plena observância das condições de oferta fixadas por esta Lei, no caso de todas as redes escolares; b) Atingimento de taxa líquida de escolarização de pelo menos 95\% (noventa e cinco por cento) da faixa etária de sete a 14 anos, no caso das redes escolares públicas; c) Não redução média de recursos por aluno do Ensino Fundamental na respectiva rede pública, resultante da incorporação dos alunos de seis anos de idade [...] (Artigo 87, § $3^{\circ}$, incluída pela Lei $n^{\circ} 11.114$, de 2005).
} 
ensino, dentre elas, a ampliação da duração do Ensino Fundamental. O documento afirma a ampliação do Ensino Fundamental obrigatório para nove anos, a partir dos 6 anos de idade, para todos os brasileiros e, portanto, uma política afirmativa que requer de todas as escolas e de todos os educadores compromisso com a elaboração de um novo projeto políticopedagógico para o Ensino Fundamental, bem como para o consequente redimensionamento da educação (BRASIL, 2005b).

É importante ressaltar que os relatores indicam ainda que cada sistema de ensino seja livre para elaborar, com sua comunidade escolar, alternativas que visem à educação de melhor qualidade e à obrigatoriedade do Ensino Fundamental de nove anos. Cada sistema deve refletir e proceder aos devidos estudos, com a democratização do debate envolvendo todos os segmentos interessados, sendo assim a importância do trabalho coletivo na escola. Já o Parecer CNE/CEB n. 18/2005 (BRASIL, 2005c) é publicado com o objetivo de oferecer orientações para a matrícula das crianças de 6 anos de idade no Ensino Fundamental obrigatório e tece algumas considerações, ${ }^{2}$ dentre as quais se destaca que cada sistema é também responsável por refletir e proceder aos devidos estudos juntamente com os segmentos interessados, antes de optar pela(s) alternativa(s) julgada(s) mais adequada(s) à sua realidade, em função dos recursos financeiros, materiais e humanos disponíveis. Já a legitimidade e a efetividade desta política educacional exigirão ações formativas da opinião pública e das condições pedagógicas e administrativas.

No âmbito do Estado de São Paulo, a Indicação CEE $n^{\circ}$. 52/2005 considera que a Lei $n^{\circ}$. 11.114/05 é contraditória, pois antecipa a escolaridade obrigatória, mas não institui o Ensino Fundamental de nove anos. Além disso, ao destacar que essa ampliação do Ensino Fundamental é demanda de uma ampla maioria da comunidade de educadores no Brasil e em São Paulo, aponta alguns aspectos importantes, principalmente relacionados à garantia de nove anos de escolaridade básica aos que ingressaram no Ensino Fundamental com 6 anos até dezembro de 2005 e de que as crianças com 6 anos completos ou a completar até dezembro de 2005 terão direito à matrícula no primeiro ano do Ensino Fundamental. Merece maior atenção a alínea que estabelece que o primeiro ano do Ensino Fundamental deverá man-

\footnotetext{
${ }^{2}$ a) A obrigatoriedade de matrícula a partir dos seis anos de idade é reivindicação antiga no campo das políticas públicas; a ampliação é uma política afirmativa da equidade social, dos valores democráticos e republicanos; b) O projeto político-pedagógico da escola deve considerar as condições sociais e educacionais das crianças para nortear-se para a melhoria da qualidade da formação escolar; c) E cada sistema de ensino é livre para construir seu plano de universalização e de ampliação do Ensino Fundamental. (Parecer $n^{\circ}$ 18/2005)
}

ter sua identidade pedagógica e de instalações muito mais próxima dos dois últimos anos da Educação Infantil do que dos quatro anos restantes da primeira fase do próprio Ensino Fundamental.

Em 2006 é publicada a Lei Nacional $n^{\circ} .11 .274$ de 6 de fevereiro, que altera a redação dos Artigos $29^{\circ}, 30^{\circ}, 32^{\circ}$ e $87^{\circ}$ da LDBEN n'. 9394/96 e dispõe, finalmente, de forma clara e objetiva, sobre a duração de nove anos para o Ensino Fundamental com matrícula obrigatória a partir dos 6 anos de idade. A referida Lei determina, em seu penúltimo artigo, que os municípios, os Estados e o Distrito Federal terão até 2010 para a implantação e implementação da referida obrigatoriedade.

No mesmo ano, foram publicados outros $\mathrm{Pa}$ receres, uma Deliberação, uma Resolução e uma Indicação ${ }^{3}$ nos âmbitos nacional e estadual (São Paulo). Cabe destacar que, nacionalmente, são evidenciados alguns pontos comuns no que diz respeito à fixação da idade cronológica de 6 anos para o ingresso no Ensino Fundamental: não se trata de uma medida aleatória, devendo estar baseada no desenvolvimento integral das crianças da Educação Infantil; significa um novo projeto político-pedagógico do Ensino Fundamental e o redimensionamento da Educação Infantil; a partir do momento que a criança ingressa com 6 anos estará matriculada no Ensino Fundamental de nove anos, como direito público subjetivo do cidadão e dever assumido pelo poder público responsável pela manutenção da escola onde a matrícula foi efetuada.

Em termos estaduais, é enfatizada a ideia de que as equipes escolares terão que estar atentas para a necessidade de: articulação entre as demandas e as características da Educação Infantil e dos anos iniciais do Ensino Fundamental, procurando prever mecanismos de interação entre família, escola e comunidade; preservação da continuidade formativa que se estende ao longo dos seis anos; qualificação didática e flexibilidade dos tempos escolares. Enfim, que

[...] a ampliação do Ensino Fundamental obrigatório de nove anos, a partir dos 6 anos de idade, é uma política afirmativa que requer, de todas as escolas e de todos os educadores, compromisso com a elaboração de um novo projeto pedagógico para o Ensino Fundamental, bem como para o consequente redimensionamento da Educação Infantil. (SÃO PAULO, 2006).

Os municípios do Estado de São Paulo vivenciaram, de forma mais acentuada, a elaboração da proposta após a promulgação da Lei citada anteriormente. Isso decorre da ideia apontada por Cury (2006, p.17), que afirma que uma Lei, quando apro-

\footnotetext{
${ }^{3}$ Parecer CNE/CEB no 39/2006; Parecer CNE/CEB n' 41/2006; Deliberação CEE n 61/2006; Indicação CEE nº 63/2006.
} 
vada, tem um "poder fático". Ela é um fato que se impõe, pela democracia representativa, em um Estado democrático de direito. Nessa medida, ela se institui como um campo de referência, de significação e de obrigação.

Na Resolução de 7 de abril de 2008 foi homologada, com fundamento no artigo $9^{\circ}$ da Lei $n^{\circ}$ 10.403 de 6 de julho de 1971, a Deliberação CEE n $73 / 2008$, que regulamenta a implantação do Ensino Fundamental de nove anos no âmbito do Sistema Estadual de Ensino, conforme disposto na Emenda Constitucional $n^{\circ} 53$ e na Lei $n^{\circ} 9.394 / 96$, com as alterações procedidas pela Lei $n^{\circ} 11.274 / 2006$. O Art. $3^{\circ}$ explicita a implementação do Ensino Fundamental de nove anos no Estado de São Paulo e a preservação da identidade da Educação Infantil. Assim, a lei estabelece, para 2009, os seguintes limites: na $1^{\text {a }}$ fase da pré-escola para 4 anos a completar até 30/06/09; na $2^{\text {a }}$ fase da pré-escola para 5 anos a completar até 31/12/09; no $1^{\circ}$ ano do Ensino Fundamental para 6 anos a completar até 31/12/09.

O Parecer $n^{\circ} 73$ de 04 de abril de 2008 define pontos importantes que devem nortear a implementação do Ensino Fundamental de nove anos no Estado de São Paulo, estando especialmente alerta aos seguintes problemas a serem evitados pelos sistemas educacionais: a) Fazer com que as crianças sejam compelidas a cumprir dois anos do mesmo programa escolar; b) Fazer com que as crianças sejam compelidas a "pular" uma fase da escolaridade.

Por se tratar de um tema complexo, a proposta da pesquisa partiu do pressuposto de que o Ensino Fundamental de nove anos poderia e ainda deve ser contemplado sob vários olhares e pontos de vista científicos. A pesquisa contemplou a realidade em construção, as reformas educacionais no momento em que elas aconteceram e, além disso, focalizou a escola e seus atores como reais construtores do processo educacional. Assim, procurou-se diagnosticar a percepção das equipes de direção e da dirigente, os problemas vivenciados, os êxitos do processo e as maiores dificuldades. Destaca-se que outros olhares também são fundamentais, como, por exemplo, o impacto para os docentes, funcionários, alunos e pais. Entretanto, foi preciso delimitar o olhar das pesquisadoras, optando-se, neste primeiro momento, pelo segmento dos administradores escolares.

Concorda-se com Silva Jr. e Ferretti (2004) quando afirmam que:

[...] a instituição escolar não é mera agência reprodutora de expectativas ou projetos sociais, uma vez que, como resultado do próprio processo histórico, cada unidade escolar, ao mesmo tempo em que incorpora valores, normas, procedimentos, etc., socialmente instituídos, constrói sua própria forma de ser e de se organizar, elabora normas e valores, estabelece condutas, costumes, códigos e referências que utiliza coletivamente como critérios para examinar, analisar, incorporar, negar ou modificar o que lhe é proposto por meio da prática escolar, cuja centralidade constitui-se no indissociável binômio apropriação-objetivação. (p. 45).

Com base nesse referencial e em uma perspectiva histórica da administração escolar, foram colhidos e analisados os dados da pesquisa, apresentados a seguir.

\section{Os entrevistados e suas percepções em relação à concretização do ensino de nove anos}

Para a totalidade dos entrevistados, o ensino de nove anos foi algo que suscitou preocupações, medos e lançou, em um primeiro momento da entrevista, vários questionamentos, dentre os quais se evidenciam: Haverá prejuízos para as crianças se forem matriculadas no Ensino Fundamental aos 6 anos? Ela perderá a infância? E o lúdico, o brincar? Ela suportará a rotina do Ensino Fundamental? E a estrutura física das escolas comporta receberem essas crianças tão pequenas? E quanto aos banheiros, as carteiras, os recreios, as saídas e entradas e o parquinho? Os professores saberão trabalhar com elas? Precisarão de uma formação específica? No $1^{\circ}$ ano primeiro vamos alfabetizar?

A diretora 5, por exemplo, ao ser questionada sobre sua percepção, respondeu de imediato: "Um avanço", acrescentando em seguida: "Nós começamos com bastante medo." No mesmo sentido, a diretora 2 diz que "[...] em primeira instância eu fiquei meio assustada. Mas depois, fomos crescendo juntas, acho que foi um passo para melhor". As respostas indicam que as equipes diretivas do município analisado, durante o período de implantação do ensino de nove anos, passaram por um processo que Ihes permitiu mudar suas percepções iniciais, vislumbrando um possível ganho para a educação.

A diretora 1, especificamente, diz que sua maior preocupação seria o modo como

[...] essas crianças iam ser recebidas (pelos professores). Eu achava assim... que eram muito pequenos. Eu achava que existia um abismo muito grande entre EMEI e EMEF. Essa mudança de El para EF. Parece que ali a criança deixa de ser criança. Ela ali não é mais criança. Mas, com o tempo, começamos a estudar tudo. E depois, chegaram reorganização, classes, espaços.

A diretora 3 destaca os aspectos que antecederam o processo de concretização do ensino de nove anos, especialmente o preparo dos docentes, que Ihe pareceu suficiente: "O Ensino Fundamental de nove anos, no começo, assustou a todos. Mas 
nós fomos bem preparadas [...] a preocupação era com o lúdico mesmo." A diretora 6 demonstra também muitas preocupações iniciais, vinculadas, sobretudo, aos aspectos estruturais e pedagógicos:

[...] o primeiro momento foi pensar na parte física da escola. Porque a gente compara e sempre acaba discutindo quem daria essa aula, quem viria para cá, como seria essa escola, como seria o recreio, como seria a entrada e a saída. Seriam cinco horas com essa criança aqui na escola! Como trabalhar com ela? E o que nós vamos fazer? Só tem cimento na escola! Não tem banco de areia, não tem sala de arte, biblioteca. Tinha sala de vídeo, uma quadra muito boa. E essas crianças ficariam cinco horas sentadas nessa cadeira e...

A Secretária Municipal de Educação encara o ensino de nove anos como um desafio. Desafio este que lhe deu a oportunidade de demonstrar o potencial profissional construído ao longo de sua trajetória como educadora. A profissional defende os ganhos para as crianças e, principalmente, indica pontos favoráveis da proposta em concretização. Para ela, é preciso contar com "[...] gestores que pensem mesmo numa gestão pedagógica e participativa, mas que entendam mesmo!" Esse, no entanto, é um processo que precisa ser gerenciado, conduzido "[...] saber gerenciar essa educação de qualidade, saber conduzir essa equipe coletivamente..." Não basta, segundo a entrevista, somente o envolvimento da equipe diretiva, deve haver o comprometimento de toda equipe da escola, principalmente dos professores.

Neste sentido, ela destaca que todos os profissionais da educação têm de "[...] vestirem a camisa... Esse compromisso tem como principio norteador a criança que não pediu para estar lá, [...] terem esse compromisso com a criança de 6 anos que não pediu para estar lá, mas que está e agora é nosso dever é fazer dar certo! [...] ainda considero o Ensino Fundamental de nove anos um grande desafio!"

Em relação aos êxitos e dificuldades, os entrevistados indicam, sobretudo, que os vivenciam na interação entre o instituído e o instituinte. ${ }^{4}$ Mas de forma geral, os problemas concentraram-se nos âmbitos político e pedagógico e os êxitos em aspectos pedagógicos pontuais.

A partir do questionamento sobre os problemas vivenciados, a Secretária relatou que "os diretores trabalhavam muito com a visão dos professores de Ensino Fundamental numa primeira série já com letramento. Eles entravam num período de adaptação, e era difícil para as crianças. Então, nós tivemos que colocar os diretores em contato com a Edu-

\footnotetext{
4 Instituído entendido como algo proveniente de situações de estabilidade ou consensual e instituinte como os momentos de instabilidade e/ou conflito, por originar-se da prática e da interação com o que foi instituído. Ver mais a respeito: BRZEZINSKI (2007).
}

cação Infantil. Eles foram várias vezes lá assistir, ver como que era o rodízio." 5

Um aspecto evidenciado pela maioria dos entrevistados representa mais um desafio a ser enfrentado na concretização do ensino de nove anos do que em um problema, a saber: "[...] não tirar a infância da criança." (DIRETORA 2). Um dos entrevistados destacou que as crianças "tinham medo que, se fossem para a escola, acabariam perdendo o parque, a fase de brinquedo. Elas continuam vindo aqui! Então, a preocupação era com o brincar no parque, na sala de brinquedo. Elas ainda continuam vindo brincar". (DIRETORA 2).

A diretora 5, ao mesmo tempo em que indica essa preocupação, aponta como aspecto positivo o fato de as crianças terem amadurecido, pois, segundo a entrevistada, iniciaram a alfabetização naturalmente, além de estarem mais responsáveis e valorizadas. Complementa dizendo que "[...] nós nos surpreendemos ao ver os caderninhos, os trabalhos, a autonomia dela (criança). Vimos bastante avanço, não tivemos crianças chorando, nervosas, dando trabalho, rejeitando [...]" (DIRETORA 5).

Em continuidade à ideia, a diretora 6 faz uma longa explanação sobre os desafios que enfrentaram e que acabaram se constituindo, segundo ela, em êxitos do processo vivenciado. Afirma que, além de as crianças terem gozado de um desenvolvimento significativo, os pais também puderam sentir uma maior responsabilidade em relação à presença e frequência de seus filhos na escola, que passava, a partir daquele momento, a ser uma escola de Ensino Fundamental, exigindo, portanto, o cumprimento de determinadas regras. Sendo assim, a profissional indica que "[...] quando nós fizemos o conselho de classes e séries no primeiro bimestre, para ver o plano, que teve um prazo para ser entregue, foi um susto... a quantidade de faltas. Então, na primeira reunião com os pais desses alunos do primeiro bimestre, nós - eu e a outra diretora -, dissemos aos pais: pai. ele hoje tem boletim, ele não faz parte do ensino [ela quer dizer Educação Infantil]. Foi um susto que eles levaram. Eu acho que não queriam entender essa parte". (DIRETORA 6).

Outros êxitos do processo, segundo a percepção dos entrevistados, são: o tempo disponibilizado para a reflexão e estudo coletivos; o envolvimento e comprometimento de cada um e de todos com a criança; adaptação das crianças ao ritmo da escola de Ensino Fundamental.

Em relação ao primeiro, a diretora 3 identifica que o profissional da educação do município "[...]

\footnotetext{
${ }^{5} \mathrm{O}$ rodízio diz respeito às atividades de Educação Infantil que os diretores construíram para que os outros diretores pudessem conhecer a matriz curricular específica que trabalha com o lúdico, o movimento e as artes visuais.
} 
está sempre se reciclando, tanto o diretor como o professor, e a ele foi destinado, pelo governo municipal, mais horas para estudo coletivo". Quanto ao segundo aspecto, ficou explícito, em grande parte das entrevistas, o quanto as profissionais têm carinho pelo ambiente de trabalho e, nesse sentido, buscaram o envolvimento de todos no que estava sendo concretizado. A diretora 1, por exemplo, diz que "[...] eu acho que tem que ter gente comprometida. O principal desse nosso sucesso eu acho que é esse comprometimento de casa mesmo. Desde o jardineiro; de todo mundo. Quando eu pisei o pé aqui como diretora eu disse: nossa missão é a criança, nós estamos aqui porque aqui é uma escola infantil, porque aqui tem criança. Se não tivesse criança não tinha porque a gente estar aqui. Então, nossa missão é a criança. Se você caminhar pela escola sem ninguém saber quem você é, você vai ver que o Senhor J, o jardineiro, tá aí! Ele pára às vezes de roçar, de varrer e vai amarrar tênis, vai tirar uma criança que está em lugar que pode ser perigoso, que pode ter ido ao banheiro e dado uma fugidinha da professora [...]" (DIRETORA 1).

A maioria dos entrevistados identifica como um dos principais êxitos a adaptação da criança, mais cedo, ao ritmo e estrutura do Ensino Fundamental, com sua ordem, tarefas e tempo de permanência na escola. A diretora 5 é uma das que sustentam esse discurso, ao afirmar que "[...] as crianças vão para o $2^{\circ}$ ano já com uma forma de alinhamento, já estão as cinco horas dentro da escola, elas entram mais cedo". A diretora 6 , na mesma direção, destacou que "[...] agora as professoras querem pegar o segundo ano [...] as crianças já têm um comportamento de carteira, assim, sentados nas carteiras em duplas diferentes da Educação Infantil, que são mesinhas em quatro, redondinhas. Então, foi uma adaptação total do ambiente físico da escola, de dentro da sala de aula e da localização da escola também."

Ao serem indicados os problemas de naturezas pedagógica e política, não se pensou na possibilidade de divorciá-los, uma vez que, no dizer de Freire (1991), ${ }^{6}$ todo ato pedagógico é também um ato político. Entretanto, é possível identificar na fala das entrevistadas que a dificuldade maior concentrou-se no "convencimento" dos pais e dos outros profissionais da educação, bem como nos problemas pedagógicos mais relacionados aos aspectos de estrutura física e às adaptações às idades das novas crianças que ingressavam na escola naquele momento. Não foi possível diagnosticar problemas relacionados à discussão do processo pedagógico, à participação da comunidade em tomadas de de-

\footnotetext{
${ }^{6}$ Para o desenvolvimento da pesquisa, optou-se por focalizar esta obra de Freire (1991), justamente porque é a que contempla mais diretamente as questões relacionadas à administração da educação. Ver mais a respeito em LIMA, 1998, LIMA, 2002.
}

cisão e à construção/alteração do projeto políticopedagógico da escola. Nesse sentido, os maiores problemas diagnosticados referiram-se a aspectos operacionais, e não político-ideológicos. Esse fato se explicita também no discurso das diretoras, que demonstram ter de explicar, convidar e convencer os pais de que seus filhos não perderiam, mas sim ganhariam, com a concretização do Ensino Fundamental de nove anos. Vale transcrever duas falas: "O maior (problema) foi falar com esses pais que iam trazer essas crianças para gente." (DIRETORA 5).

Como a gente trabalha em parceria, o problema maior estava em falar com esses pais que iam mandar essas crianças para gente. Era convencêlos a tirar os filhos de uma escola pequena, onde as crianças ficavam todas juntas, que era a Educação Infantil. E aí, junto com a dirigente, fizemos reuniões [para alcançar tal objetivo]. (DIRETORA $6)$.

Para encerrar a análise, que certamente não conseguiu abranger a riqueza e a multiplicidade dos olhares dos entrevistados, destaca-se que a administração do sistema e das escolas apresenta uma percepção bastante benéfica da concretização da escola de nove anos. Mesmo quando os entrevistados contemplam os problemas advindos do processo, indicam que se caracterizaram mais como desafios do que como problemas. Vale ressaltar, ainda, que o contexto que antecedeu a concretização do ensino de nove anos no município foi caracterizado pelo delineamento, pela compreensão da legislação, pela encampação da ideia e pelo convencimento da equipe, o que pode ter contribuído para a percepção diagnosticada.

Finalmente, algumas falas que sinalizam para as considerações finais realizadas:

Se nós errarmos, temos que corrigir os erros. Podemos perder uma batalha, mas não a guerra! Nós temos que ter sucesso! Vamos começar achando que vai dar certo! Então, nisso a equipe tá acreditando, sabe! Mas ainda considero um grande desafio! (DIRIGENTE).

E, nas palavras da diretora 6: "Que as outras implantem o quanto antes e não esperem o último ano para implantar. Porque vale a pena em todos os sentidos pedagógicos, na ambientação, no tempo, na parte dos pais."

\section{Administração escolar e as reformas educacionais - algumas considerações}

A revisão de bibliografia precedeu a coleta de dados, entretanto, indicou a dificuldade de estabelecer um referencial teórico fechado que possibilitasse a leitura e análise do material advindo da transcrição da entrevista. Os maiores problemas foram ori- 
ginados da ausência de autores que contemplam a temática do Ensino Fundamental de nove anos do ponto de vista da administração escolar. Nesse sentido, optou-se, ao construir o projeto de pesquisa, por realizar uma trajetória histórica, ainda que breve, da área, para que a partir dela pudessem ser buscadas as "chaves de leitura".

Nesse momento, constatou-se que as primeiras discussões sobre a administração escolar foram realizadas com base na administração de empresas, sendo identificados vários autores representativos das discussões com essa perspectiva (RIBEIRO, 1968; ALONSO, 1976).

A década de 1980 é marcada pela crítica à abordagem anterior e conta com autores que propõem uma nova abordagem para a administração escolar, baseada, sobretudo, na especificidade da escola e no trabalho coletivo mediante a vivência de uma gestão democrática (PARO, 1986; FREIRE, 1991).

Cogitou-se estabelecer uma análise das entrevistas sob uma perspectiva freireana, entretanto, outros autores ofereceram suporte para a leitura do material. Considera-se, em linha geral, que a legislação indicou uma possibilidade democrática, de vivência coletiva na escola, para a elaboração de um projeto político pedagógico que concretizasse um novo ensino de nove anos. Contudo, quando da análise das entrevistas, evidenciaram-se preocupações nitidamente operacionais de "como realizar da melhor forma possível" e não de "por quê", ou "com quais objetivos", questões de caráter mais políticopedagógico do que técnico. Assim, as falas se distanciaram sobremaneira da perspectiva freireana.

Destaca-se da leitura e análise da legislação a afirmação de que o Ensino Fundamental obrigatório de nove anos exige que todo o sistema de ensino se comprometa em laborar seu projeto político-pedagógico de forma democrática, que envolva outros segmentos na reflexão e nos procedimentos provenientes de estudos. Não foi possível identificar, a partir das entrevistas, mesmo que informalmente, a participação da comunidade educativa na construção do um projeto político pedagógico. Embora tenha existido a intenção de coletividade, ela ficou restrita ao processo de formação de uma equipe escolar sintonizada com a concretização da proposta.

A perspectiva das entrevistas se distancia, de certa forma, da abordagem de Paulo Freire (1991), que defende que as decisões são partes dos sujeitos reflexivos de suas próprias práticas. Para o autor, o sujeito deve, primeiramente, compreender a razão de ser da própria prática e, em seguida, tornar-se capaz de ter uma prática melhor, pensando, assim, na experiência como prática inserida na prática social de forma séria e indispensável. O que Freire (1991) considera lamentável é separar mecanicamente o mundo da prática do mundo da teoria.

A fala das entrevistadas se aproxima, de certa forma, da concepção de Alonso (1976), que defende a adaptação aos fatores internos e externos do sistema escolar, para que ele se mantenha em equilíbrio. Foi possível perceber que algumas falas reforçam essa abordagem:

[...] acho que isso ${ }^{7}$ aí foi o que também acalmou o coração dos pais, por que eles estavam bastante agoniados com a mudança. Falavam: 'Como vai ser isso?' 'Como vai ser aquilo?' Porque nós fizemos várias reuniões com os pais e com a comissão (explica). 'Então, como vai ser o transporte?' 'Como vai ser o brincar?' 'Como vai...' 'E o recreio com os grandes?' Era assim com a maioria dos pais. (DIRETORA 4).

E quando a pesquisadora pergunta quantos pais participavam efetivamente do processo, a diretora 3 diz:

Então, constantemente a gente tem ligação com os pais. Não pode vir na reunião à gente chama, atende em outro horário. É urgente o atendimento... Aqui acontece alguma coisa eu transporto até com meu carro (Diminui o tom). Então, porque a prioridade aqui é criança. E sem eles nossa profissão não tem função. (DIRETORA 3).

Percebe-se que, por um lado, as entrevistadas dizem que há uma participação dos pais, salientando que eles estavam agoniados com a mudança; por outro, quando questionadas sobre o número de pais que participavam, elas demonstram que não há uma participação significativa. Foi possível perceber, ainda, que alguns pais participam do conselho, enquanto outros são convocados somente quando se diagnosticam problemas pontuais: "Ah! Sempre tem aqueles mais envolvidos. Na verdade, eram quase todas mães, tinha só um pai. Mas oito é que estavam envolvidos, os outros vinham pelo conselho". (DIRETORA 1).

Não foi possível perceber a tomada de decisão coletiva e/ou ações coletivas, entretanto, é preciso ressaltar que a construção da participação popular é um processo lento, difícil, conflituoso, que demanda tempo e trabalho (LIMA, 1998). A participação não pode ser entendida como um slogan, como uma maneira de "vender mercadorias", devendo ser incorporada, vivida e praticada. Para Freire (1991), somente intenções e atitudes democráticas não são suficientes: é preciso criar nas unidades escolares uma cultura de participação que reúna todos os en-

\footnotetext{
${ }^{7}$ Ela se refere ao fato de a administração da educação municipal de Pompéia ter optado por remanejar os professores adidos na Educação Infantil (pré III) para o Ensino Fundamental. As diretoras acreditam que esse procedimento (a professora que acompanhava a criança na educação foi com a criança para o Ensino Fundamental) tranquilizou os pais.
} 
volvidos no processo educacional, possibilitando a propagação de todas as informações necessárias ao debate e à tomada coletiva de decisão.

Essas discussões vão ao encontro da abordagem de Machado (2008), que constrói uma crítica à gestão participativa, contrapondo-a à administração tradicional e propondo "[...] o 'ponto correto' de inflexão da 'vara administrativa', ou, para usar a denominação corrente, a busca de um "novo padrão de gestão". (p.57).

A autora se refere à revitalização da figura do diretor de escola como dirigente escolar como sendo um dos elementos fundamentais. Para a autora, a gestão democrática e a participação da comunidade na gestão das unidades escolares não devem ser descartadas. No entanto, para que isso ocorra na prática, é necessário objetivo educacional e de gestão colocados com clareza e sinceridade. O diretor articulador do projeto pedagógico da escola resgata sua função e se fortalece numa atuação dinâmica e globalizante que não "[...] descuidaria do "clássico", em administração: planejar, organizar, coordenar, dirigir e avaliar; uma atuação voltada para a materialidade da educação, criando condições necessárias, nas quais ocorre a Educação" (MACHADO, 2008, p. 58. Grifo da autora).

Assim, ao articular o projeto pedagógico da escola, o diretor, ou a direção

[...] criaria, a cada momento, as condições de partiIha do poder, que é o sentido mais puro da participação, garantindo a possibilidade de surgimento de um verdadeiro trabalho coletivo, em que o conhecimento global da escola cimentaria as relações entre os interessados no processo educativo, o que possibilitaria a emergência de outro fator essencial: a transparência e, finalmente, centraria a escola na função de ensino. (MACHADO, 2008, p.58).

As reflexões até o momento realizadas permitem inferir que a realidade das escolas, do ponto de vista administrativo, distancia-se das abordagens teóricas que defendem a participação coletiva na tomada de decisão efetiva. Lança-se aqui um questionamento: em que medida a participação é possível e viável nas condições atuais que estruturam a sociedade e o sistema educacional - principalmente, quando pensamos que as próprias reformas e propostas não se originam da vontade e necessidade dos integrantes da comunidade educativa?

\section{Referências}

ALVES, M. L. A escola de nove anos: integrando as potencialidades da Educação Infantil e do Ensino Fundamental. Disponível em: <http://www.multimeios.ufc.br/ artigos.php>. Acesso em: 3 out. 2007.
ALONSO, M. O papel do diretor na administração escolar. São Paulo: Difel, 1976.

BRZEZINSKI, I. Formação de professores para a Educação Básica e o curso de Pedagogia: a tensão entre o instituído e o instituinte. Revista Brasileira de Política e Administração da Educação, v. 23, p. 229-251, maio/ ago. 2007.

BRASIL. Lei n. 4024/1961 de 20 de dezembro de 1961. Estabelece as diretrizes e bases da educação nacional. Diário Oficial da União, 27 dez. 1961. Disponível em: <http://portal.mec.gov.br/arquivos/pdf/ldben.pdf>. Acesso em: $1^{\circ}$ ago. 2007.

Lei $n^{\circ}$. 5692/1971 de 10 de agosto de 1971. Fixa as diretrizes e bases para o ensino de $1^{\circ}$ e $2^{\circ}$ graus e dá outras providências. Diário Oficial da União, Brasília, 12 ago. 1971. Disponível em: <http://www.planalto.gov.br/ CCIVIL/LEIS/L5692.htm>. Acesso em: $1^{\circ}$ ago. 2007.

Lei $n^{\circ}$. 9394/96 de 20 de dezembro de 1996. Estabelece as diretrizes e bases da educação nacional. Diário Oficial da União, Brasília, 23 dez. 1996. Disponível em: $<$ http://portal.mec.gov.br/arquivos/pdf/ldben.pdf>. Acesso em: $1^{\circ}$ ago. 2007.

Lei $n^{\circ}$. 10.172/ 2001. Estabelece o Plano Nacional de Educação. Diário Oficial da União, Brasília, 10 jan. 2001. Disponível em: <http:// portal.mec.gov.br/arquivos/ pdf/pne.pdf>. Acesso em: $1^{\circ}$ ago. 2007.

Lei $n^{\circ}$. 11.114, de 16 de maio de 2005. Altera os arts. $6^{\circ}, 30,32$ e 87 da Lei $n^{\circ} .9 .394$ de 20 de dezembro de 1996. Diário Oficial da União, Brasília, 17 maio 2005a. Disponível em: <http://www.planalto.gov.br/ccivil_03/_ Ato2004-2006/2005/Lei/L11114.htm>. Acesso em: $1^{\circ}$ ago. 2007.

MEC. CNE. Parecer CNE/CEB $n^{\circ}$. 6/2005. 2005b. Disponível em: <http://www.mec.gov.br>. Acesso em: $1^{\circ}$ ago. 2007.

MEC. CNE. Parecer CNE/CEB no 18/2005. 2005c. Disponível em: <http://www.mec.gov.br>. Acesso em: 2 ago. 2007.

BRASIL. Lei $n^{\circ}$. 11.274, de 06 de fevereiro de 2006. Altera os arts. 29, 30, 32 e 87 da Lei $n^{\circ} 9.394$ de 20 de dezembro de 1996. Diário Oficial da União, Brasília, 7 fev. 2006. Disponível em: <http://www.planalto.gov.br/ ccivil_03/Ato2004-2006/2006/Lei/L11274.htm>. Acesso em: $\overline{1^{\circ}}$ ago. 2007.

CURY, C R. J. LDB: Lei de Diretrizes e Bases da Educação (Lei $n^{\circ}$ 9.394/96). 10. ed. Rio de Janeiro: DP\&A, 2006.

FREIRE, P. Educação na cidade. São Paulo: Cortez, 1991.

LIMA, L. Organização escolar e democracia radical. São Paulo: Cortez, 1998.

LIMA, M. R. C. de. Administração da educação na década de 1990: entre a competitividade e a humanização. 2002. 125 f. Dissertação (Mestrado em Educação) - Faculdade de Filosofia e Ciências de Marília, Marília, 2002.

MACHADO, L. M. Quem embala a escola? In: MACHADO, L. M.; MAIA, G. Z. A. Administração e Supervisão escolar: questões para o novo milênio. 2. ed. Marília: M3T Tecnologia e Educação, 2008. 
PARO, V. H. Administração escolar: introdução crítica. São Paulo: Cortez: Autores Associados, 1986.

RIBEIRO, J. Q. Introdução à administração escolar (alguns pontos de vista). In: ANPAE. Administração Escolar: edição comemorativa do I Simpósio Interamericano de Administração Escolar. Salvador: ANPAE, 1968. p. 18-40.

SÃO PAULO. CONSELHO ESTADUAL DA EDUCAÇÃO. Indicação CEE n 52/2005. Duração do Ensino Fundamental - ampliação do ensino obrigatório. Disponível em: <http://www.ceesp.sp.gov.br/Indicacoes/in_52_05.htm>. Acesso em: $1^{\circ}$ ago. 2007.

SÃO PAULO. CONSELHO ESTADUAL DA EDUCAÇÃO. Parecer CEE n 461/2005. Disponível em: <http://www. ceesp.sp.gov.br/Pareceres/pa_461_05.htm>. Acesso em: 10 ago. 2007.

SÃO PAULO. CONSELHO ESTADUAL DA EDUCAÇÃO. Deliberação CEE n 61/2006. Disponível em: <http://www. ceesp.sp.gov.br/Deliberacoes/de_61_06.htm>. Acesso em: $1^{\circ}$ ago. 2007. Não paginado.

SÃO PAULO. CONSELHO ESTADUAL DA EDUCAÇÃO. Indicação CEE n 63/2006. Disponível em: <http://www. dersv.com/Deliberacao_61_06_EF_9anos.htm>. Acesso em: 8 ago. 2007.

SILVA JUNIOR, J. dos R.; FERRETTI, C. J. O institucional, a organização e a cultura da escola. São Paulo: Xamã, 2004.

Recebido em 19/05/2009

Reformulado em 29/06/2009

Aceito $02 / 08 / 2009$ 